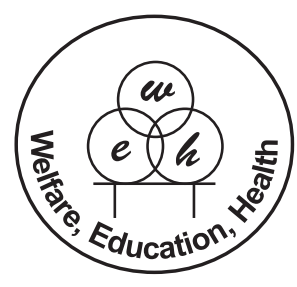

Journal of PharmaSciTech

ISSN: 22313788 (Print)

23214376 (Online)

Research Article

\title{
In vitro Antiurolithiatic Potential in Asparagus falcatus L., A Folklore Medicinal Plant in Sri Lanka
}

Mayuri Napagodaa* ${ }^{1 *}$ Nisansala Madhumadhavi ${ }^{2}$, Kanchana Vimukthi', Shamila Malkanthi', Kaumadhi Abayawardana ${ }^{1}$

'Department of Biochemistry, University of Ruhuna, Galle 80 000, Sri Lanka

2Department of Medical Laboratory Science, University of Ruhuna, Galle 80 000, Sri Lanka

Article Info:

Received: 10.04 .2019

Accepted: 16.07 .2019

Available online: 01.9.2020

*Correspondence: mayurinapagoda@yahoo.com (Tel.: +94-(0)71 92162 81)

\section{Abstract}

https://doi.org/10.33981/JPST.2020.v09i01.005

Urolithiasis is the condition where urinary calculi are formed in the urinary tract and is identified as one of the most prevalent diseases throughout the globe. However, the treatment approaches employed in modern medicine are not capable of preventing the recurrence of urinary calculi formation. In this respect, the plant species used in traditional systems of medicine to treat and/or prevent urinary calculi could be explored in order to develop novel antiurolithiatic agents. Therefore, the present study aims at evaluating the antiurolithiatic potential in Asparagus falcatus L., a plant widely employed in indigenous medicine in Sri Lanka to dissolve urinary calculi and to treat other urinary disease conditions. Thus, herein, the antiurolithiatic potential of methanolic extract of the root of $A$. falcatus was studied under in vitro conditions using crystal nucleation and aggregation assays. Furthermore, the dissolution assay was employed to determine the ability of the plant extract in dissolving surgically removed urinary calculi samples from patients and the results were expressed as percentage weight loss of calculi sample. The results of the in vitro assays revealed that the above extract is capable of preventing crystal nucleation by $13.26 \%$ and aggregation by $36.5 \%$ at the concentration of $2000 \mu \mathrm{g} / \mathrm{mL}$. Its efficacy was comparable with a marketed polyherbal combination, cystone which displayed $17.4 \%$ and $44.27 \%$ inhibition of nucleation and aggregation respectively at the above concentration. In the dissolution assay, the plant extract reduced the weight of the calculi by $5.19 \%$ in comparison to the weight loss of $4.28 \%$ in the positive control cystone. Thus, our study indicated that the roots of $A$. falcatus was a potent and promising antiurolithiatic agent while rationalizing its use in traditional medicine.

Keywords: Antiurolithiatic, Asparagus falcatus, herbal, urinary calculi

\section{Introduction}

The term "urolithiasis" is used to describe the deposition or formation of urinary calculi in any part of the urinary system [1]. It is a common health problem with an increasing prevalence of up to $20 \%$ throughout the globe [2]. The development of the calculi is related to the decrease of urine volume or the increase of excretion of calculi-forming solute materials such as calcium, oxalate, urate, cystine, xanthine, and phosphate where calcium oxalate has been identified as the most predominant component of urinary calculi [2]. A number of sequential events involved in the calculi formation, namely; urinary saturation, supersaturation, nucleation, crystal growth, aggregation of crystals, crystal retention, and, finally, the calculus formation [3].

The surgical removal of urinary calculi is gradually replacing with the modern techniques like extracorporeal lithotripsy, ureteroscopy and local calculus disruption using a high power laser, however, none of these therapeutic approaches could avoid the recurrence of renal calculi, in which the recurrence rate is estimated nearly $50 \%$ [4]. Since the pathogenesis of urolithiasis is attributed by multiple factors, still a satisfactory drug is not available for the treatment as well as to prevent the recurrence of the calculi [5]. Moreover, hypocalciuric agents employed as treatment modalities have several adverse effects which necessitate the development of novel strategies for the prevention and treatment of urinary calculi [6]. In view of the above, the medicinal plants employed in indigenous medicine to treat urinary diseases could be potential sources of novel antiurolithiatic agents.

The genus Asparagus (Family: Asparagaceae) comprises of about 100 species that are widespread in the old World [7]. Several species of Asparagus are either grown naturally or cultivated in Sri Lanka, out of which $A$. falcatus L.,("Hathawariya") and $A$. racemosus Willd., ("Heen Hathawariya") are widely employed in indigenous medicine in the country as a remedy for chronic nephritis, as an antilithic for urinary gravel and calculi as well as a diuretic agent $[8,9]$. Although both these species are considered to be equally important as herbal remedies, most of the research studies were focused on $A$. racemosus, but not on $A$. falcatus. For example, the antiurolithiatic activity in ethanolic extract of $A$. racemosus was scientifically validated by both in vitro and in vivo studies $[10,11]$ while various secondary metabolites such as shatvarin, immunoside, aspargamine $A$, aspargamine $B$ etc. have been isolated from this plant [12]. However, the scientific evidence are scarce to rationalize the extensive utility of $A$. falcatus as an antiurolithiatic agent in indigenous medicine. Thus the present study was undertaken to evaluate the antiurolithiatic activity of roots of $A$. falcatus, a plant that has been used from the time immemorial by traditional healers in Sri Lanka for the treatment of urinary calculi.

\section{Materials and Methods}

\section{Preparation of plant extract}

Roots of $A$. falcatus were collected from Gampaha district in Western Province of Sri Lanka in 2017 and the plant material was authenticated from the National Herbarium, Royal Botanical Gardens, Peradeniya, Sri Lanka. A voucher specimen (WP2017-NO 05) was deposited at the Department of Biochemistry, Faculty of Medicine, University of Ruhuna, Sri Lanka for future references. The shade dried plant materials $(20 \mathrm{~g})$ were extracted in methanol (Sigma- Aldrich) for two days. Thereafter, the liquid aliquot obtained by filtration was evaporated using a rotary evaporator (HAHNVAPOR, HS-2005V) into complete dryness and six predetermined test concentrations $(2000$, $1000,500,250,125$ and $62.5 \mu \mathrm{g} / \mathrm{mL}$ ) were prepared from this crude extract.

\section{Determination of antiurolithiatic activity}

Nucleation assay

The spectroscopic method of Hennequin et al [13] was employed with slight modifications as described by Napagoda et al. [14], to 
determine the inhibitory activity of the extracts on the nucleation of $\mathrm{CaC}_{2} \mathrm{O}_{4}$ crystals. Briefly, $\mathrm{CaCl}_{2}(4 \mathrm{mmol} / \mathrm{L})$ and $\mathrm{Na}_{2} \mathrm{C}_{2} \mathrm{O}_{4}(50 \mathrm{mmol} / \mathrm{L})$ solutions were added to artificial urine in the presence of plant extract at different concentrations in order to initiate the crystallization. The nucleation was determined by the appearance of crystals that reached a critical size and became optically detectable either in the presence of the extract or without the extract (negative control). The absorbance was measured at $620 \mathrm{~nm}$, and the percentage inhibition was calculated as $[(\mathrm{C}-\mathrm{S}) / \mathrm{C}] \times 100$, where, $\mathrm{C}$ is the turbidity without plant extract, $\mathrm{S}$ is the turbidity with plant extract.

Cystone, a marketed polyherbal formulation that could prevent the formation of lithogenic substances and disintegrate urinary calculi [15] was used as the positive control.

\section{Aggregation assay}

The method of Hess et al. [16], was used with slight modifications as described by Napagoda et al. [14] in the determination of the rate of aggregation of the $\mathrm{CaC}_{2} \mathrm{O}_{4}$ crystals. In brief, $\mathrm{CaC}_{2} \mathrm{O}_{4}$ crystals were prepared by mixing $\mathrm{CaCl}_{2}$ and $\mathrm{Na}_{2} \mathrm{C}_{2} \mathrm{O}_{4}(50 \mathrm{mmol} / \mathrm{L}$ each) which were equilibrated in a bath for $1 \mathrm{~h}$ at $60^{\circ} \mathrm{C}$. Thereafter, the solutions were cooled to $37^{\circ} \mathrm{C}$ and then evaporated. The $\mathrm{CaC}_{2} \mathrm{O}_{4}$ crystals were dissolved with Tris $(0.05 \mathrm{~mol} / \mathrm{L})$ and $\mathrm{NaCl}(0.15 \mathrm{~mol} / \mathrm{L})$ at $\mathrm{pH} 6.5$ to a final concentration of $1 \mathrm{mg} / \mathrm{mL}$. The reaction mixture was treated with the plant extract and the absorbance at $620 \mathrm{~nm}$ was recorded at 30,60 , 90, 180 and $360 \mathrm{~min}$. The percentage inhibition was calculated as [(C$\mathrm{S}) / \mathrm{C}] \times 100$, where, $\mathrm{C}$ is the turbidity without plant extract, $\mathrm{S}$ is the turbidity with plant extract. Cystone was used as the positive control.

\section{Dissolution of urinary calculi}

The method as described by Napagoda et al. [14], was used to determine the dissolution of urinary calculi. For this assay, the urinary calculi were obtained from three male patients in the age group of 3050 years who were admitted to the Teaching Hospital, Karapitiya, Sri Lanka and underwent surgical treatment. Only the patients with a prior history of urinary calculi were selected to collect the calculi samples.

The collected calculi were crushed to homogenize the sample. A sample of $60 \mathrm{mg}$ from this crushed materials was put into each of the test tubes, into which different concentrations of extracts were added. These were allowed 24,48 , and 72 hours for dissolution at $37 \pm 0.5^{\circ} \mathrm{C}$ and the weight of the calculi were obtained at each of the above time intervals. After the dissolution period, the reduction in weight and percentage weight loss were calculated using the following formula.

$\%$ Weight loss $=[(\mathrm{Wi}-\mathrm{Wf}) / \mathrm{Wi}] \times 100$ where $\mathrm{Wi}$ is the initial weight of the calculi and Wf is the final weight of the calculi.

Cystone was used as the positive control while distilled water was used as the negative control.

\section{Statistical analysis}

All experiments were conducted in duplicates and all data were presented as mean \pm standard deviation (SD). Statistical evaluation of the data was performed by one-way ANOVA using Minitab version 14 . A p value $<0.05$ was considered significant.

\section{Qualitative analysis of the urinary calculi obtained from patients}

The powdered urinary calculi were tested for the presence of inorganic and organic constituents by standard qualitative tests described by Hodgkinson [17] with slight modifications. A brief outline of the protocol employed is illustrated in Figure 1 and described in detail

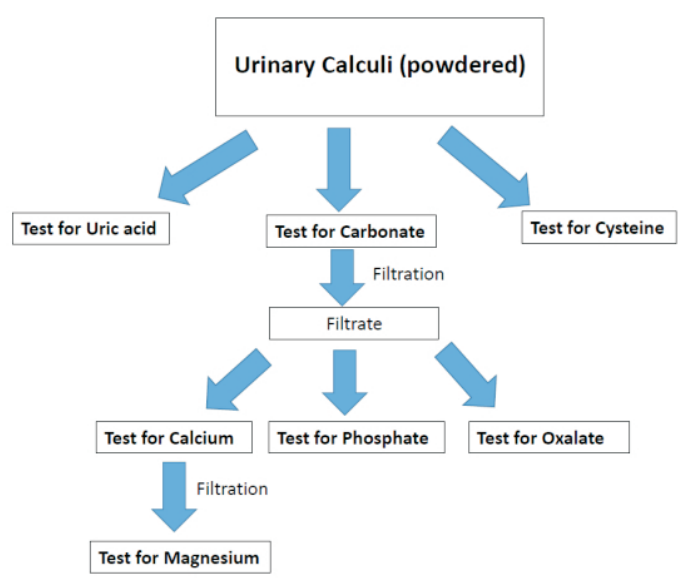

Figure 1: Testing of urinary calculi for the presence of organic and inorganic constituents

\section{Test for uric acid}

$\mathrm{KOH}$ was added to the powdered calculi sample and the filtrate was collected. Follin's reagent and $\mathrm{NaCN}$ were added to this filtrate and observed for the development of a blue colored solution.

\section{Test for cysteine}

The powdered sample was placed on a white tile into which $\mathrm{NaCN}$ and freshly prepared sodium nitroprusside solutions were added and was observed for the development of magenta color.

\section{Test for carbonate}

The powdered urinary calculi sample was treated with $\mathrm{HNO}_{3}$ acid and observed for effervesce as an indication of the presence of carbonate. Thereafter the resulted filtrate was divided into three parts and each portion was subjected to the following tests.

\section{Test for calcium and magnesium}

A few drops of $\left(\mathrm{NH}_{4}\right) 2 \mathrm{C}_{2} \mathrm{O}_{4}$ was added to the one portion of the filtrate and its $\mathrm{pH}$ was adjusted to $\mathrm{pH} 5$. The reaction mixture was observed for the presence of a precipitate.

Subsequently, this precipitate was completely filtered off and a few drops of $\mathrm{K}_{3} \mathrm{PO}_{4}$ and ammonia were added to the filtrate until it became alkaline and thereafter observed for the development of crystalline precipitate.

\section{Test for phosphate}

The second portion of the filtrate was treated with ammonium molybdate and allowed to stand at room temperature. This reaction mixture was observed for the development of yellow colored precipitate which turns blue upon the addition of reducing agents.

\section{Test for oxalate}

The third portion of the filtrate was treated with a few drops of $\mathrm{CaCl}_{2}$ and the $\mathrm{pH}$ was adjusted to $\mathrm{pH} 5$. The reaction mixture was observed for the formation of a precipitate. Thereafter, the precipitate was filtered off and the filter paper was washed with hot $0.25 \mathrm{M} \mathrm{H}_{2} \mathrm{SO}_{4}$. A few drops of diluted $\mathrm{KMNO}_{4}$ were added to this washed solution and was observed for a color change. 


\section{Ethical consideration}

Ethical approval was obtained from the Ethical Review Committee, Faculty of Allied Health Sciences, University of Ruhuna, Sri Lanka.

\section{Results and Discussion}

\section{Nucleation assay}

The pathogenesis of urinary calculi formation is a multifaceted process that involves urine saturation and super-saturation, crystal nucleation, aggregation, the retention of crystals by the urothelium, and the continued growth of the stone on the retained crystals [18]. The formation of the nucleus from supersaturated urine is the first step in the formation of urinary calculi [19], thus the classical model for the study of oxalate crystallization was employed here to study the formation and growth of the calcium oxalate monohydrate crystals from artificial urine.

The results indicated that the inhibition of nucleation was concentration dependent (Figure 2) and the maximum inhibition was observed as $13.26 \%$ for the plant extract and as $17.4 \%$ for the positive control cystone at the concentration of $2000 \mu \mathrm{g} / \mathrm{mL}$ (Figure 3). Interestingly, there was no significant difference in inhibitory potency of the test extract and the positive control $(p=0.762)$.
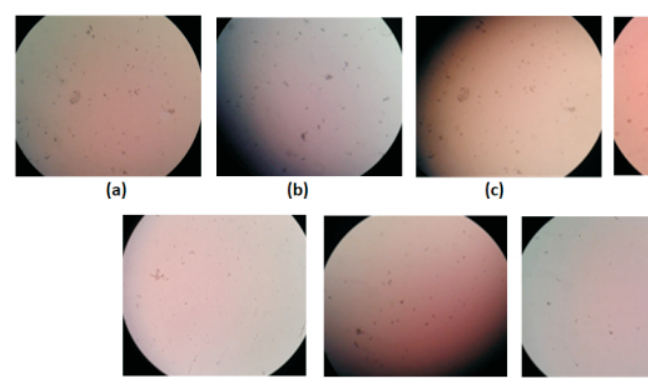

(b)

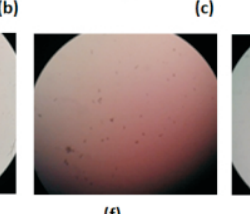

(f)

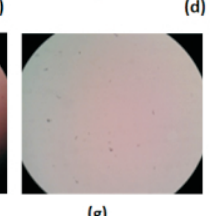

(g)

Figure 2: Microscopic evaluation of different concentrations of $A$. falcatus extract on $\mathrm{CaC}_{2} \mathrm{O}_{4}$ nucleation ( $40 \times$ magnification)

(a) Negative control (without the extract) (b) $62.5 \mu \mathrm{g} / \mathrm{mL}$ (c) $125 \mu \mathrm{g} / \mathrm{mL}$ (d) $250 \mu \mathrm{g} / \mathrm{mL}$ (e) $500 \mu \mathrm{g} / \mathrm{mL}$ (f) $1000 \mu \mathrm{g} / \mathrm{mL}$ (g) $2000 \mu \mathrm{g} / \mathrm{mL}$.

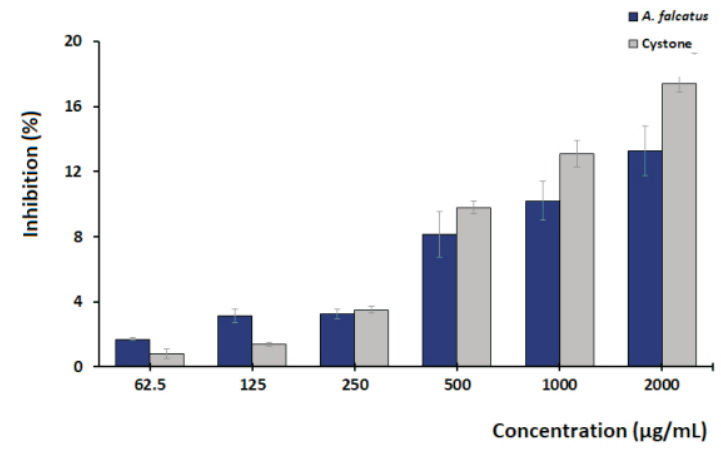

Figure 3: Effect of $A$. falcatus extract and cystone on $\mathrm{CaC}_{2} \mathrm{O}_{4}$ nucleation at different concentrations

\section{Aggregation assay}

The small hard mass of urinary crystals in solution sticks together to form larger calculi through a process known as aggregation/agglomeration which is considered to be the most critical step in calculi formation [19]. Therefore, the inhibitory potential of $A$. falcatus extract on crystal aggregation was studied (Figure 4) and compared with the commercial polyherbal remedy, cystone. The highest inhibition of crystal aggregation was observed as 36.5\% for the plant extract and $44.27 \%$ for cystone at $2000 \mu \mathrm{g} / \mathrm{mL}$ (Figure 5). The statistical analysis revealed that there was no significant difference between the inhibitory potency of the plant extract and the positive control $(p=0.518)$, indicating that both were equally effective. However, the inhibition of aggregation was not found to be time dependent.

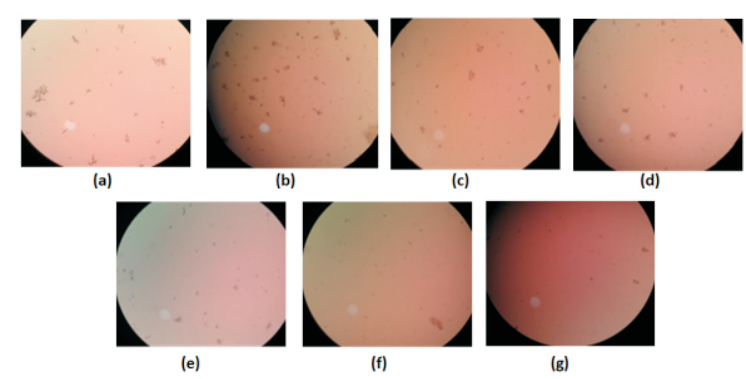

Figure 4: Microscopic evaluation of different concentration of A. falcatus extract on $\mathrm{CaC}_{2} \mathrm{O}_{4}$ crystal aggregation ( $40 \times$ magnification).

(a) Negative control (without the extract) (b) $62.5 \mu \mathrm{g} / \mathrm{mL}$

(c) $125 \mu \mathrm{g} / \mathrm{mL}$ (d) $250 \mu \mathrm{g} / \mathrm{mL}$ (e) $500 \mu \mathrm{g} / \mathrm{mL}$

(f) $1000 \mu \mathrm{g} / \mathrm{mL}$ (g) $2000 \mu \mathrm{g} / \mathrm{mL}$.

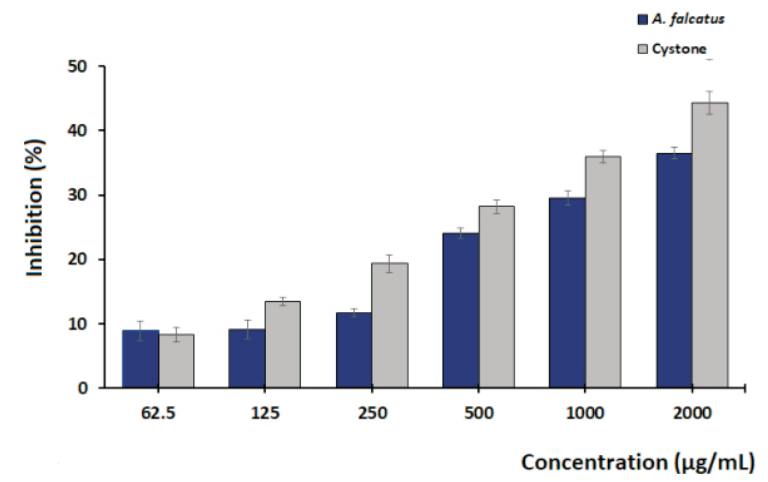

Figure 5: Effect of $A$. falcatus extract and cystone on $\mathrm{CaC}_{2} \mathrm{O}_{4}$ aggregation at different concentrations

\section{Dissolution of urinary calculi}

The efficacy in the dissolution of urinary calculi was expressed as percentage weight change at different time intervals. It was found to be time dependent as the highest mean percentage weight loss of urinary calculi was observed after 72 hours. However, the percentage weight loss was not found to be concentration dependent as the highest value was observed at $500 \mu \mathrm{g} / \mathrm{mL}$ concentration for both the plant extract and the positive control, cystone. Interestingly, the plant extract was found to be more effective than the positive control with a weight change of $5.19 \%$ in comparison to the weight change of $4.28 \%$ in the positive control (Figure 6). The statistical analysis revealed that a significance difference does exist $(p=0.04)$ between these two treatments. 


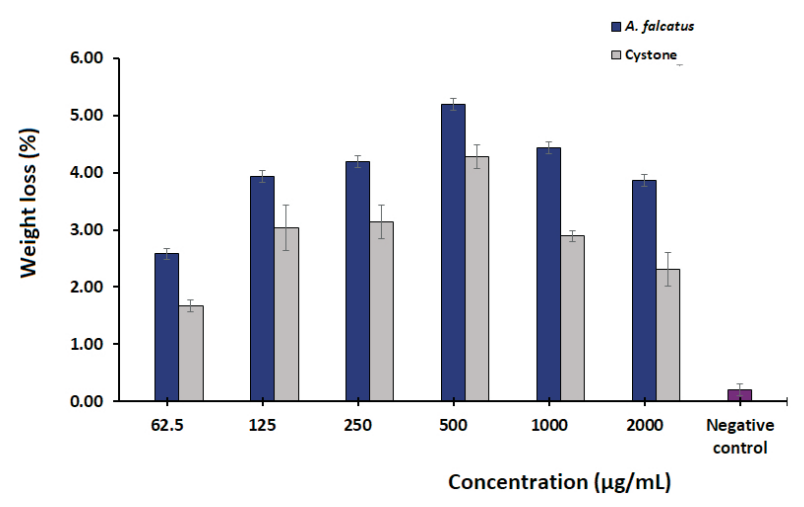

Figure 6: Effect of $A$. falcatus extract and cystone on dissolution of urinary calculi at different concentrations after incubation for 72 hours

\section{Qualitative analysis of the urinary calculi}

The results of the qualitative analysis indicated the presence of carbonate, calcium, magnesium, phosphate, oxalate, uric acid and cysteine in the urinary calculi used in the dissolution assay.

Due to the unavailability of effective drugs to be used in the clinical therapy to prevent the recurrence of urinary calculi, as of recent time, the traditional medicinal plants have drawn the attention as potential sources to be explored as alternative antiurolithiatic agents. In this respect, we assumed that the present study could provide valuable insight into the field of herbal antiurolithiatic agents while validating the ethnobotanical significance of $A$. falcatus in the Sri Lankan folklore medicine.

In this work, the effect of $A$. falcatus extract on the calcium oxalate crystal nucleation and aggregation as well as the dissolution of urinary calculi composed of calcium, magnesium, phosphate, carbonate, oxalate, uric acid and cysteine were evaluated. These in vitro investigations revealed that $A$. falcatus is highly effective as an antiurolithiatic agent by inhibiting the calcium oxalate crystal nucleation and aggregation in a concentration-dependent manner, similar to the positive control, cystone. Moreover, the plant extract is potent in the dissolution of urinary calculi and this potency surpassed that of cystone. The standard drug cystone has been identified as an effective formulation for the treatment of urolithiasis where the antilithiatic effect has been attributed to complex spectrum of actions including antimicrobial, diuretic, antispasmodic, litholytic, antiinflammatory and anticalcifying activities of its ingredients [20]. However, under in vitro conditions, it is possible to hypothesize that the litholytic and anticalcifying potencies of cystone would make significant contributions to its antilithiatic effect, as other bioactivities are imposed mainly under in vivo situations. Similarly, the methanolic extract of $A$. falcatus may also exert several modes of actions that could be correlated with its antilithiatic effect, in addition to its anticalcifying and litholytic potencies observed in this in vitro study. Thus, more detailed in vivo experiments are required to elaborate the other possible underlying mechanisms involved with the antilithiatic activity of this extract. Nevertheless, the observed potencies in the extract are advantageous for the development of a product which is capable of preventing urinary calculi formation as well as to be used as an effective alternative therapy for urinary calculi. The observed bioactivities could be attributable to the presence of antiurolithiatic phytochemicals in this extract, thus phytochemical analysis is warranted to identify the bioactive secondary metabolites while the scientific validation of its efficacy and safety could be achieved by detailed in vivo assays and cytotoxicity studies.

\section{Conclusion}

Our investigations indicated that under in vitro conditions, methanolic extract of the root of $A$. falcatus has a potent antiurolithiatic activity due to its inhibitory effects on the crystal nucleation, aggregation as well as dissolution of urinary calculi and these observations rationalize the folklore claims of this plant as an effective antiurolithiatic agent.

\section{Acknowledgement}

The authors are grateful for Department of Biochemistry, Faculty of Medicine and Department of Medical Laboratory Sciences, Faculty of Allied Health Sciences for providing laboratory facilities to conduct this study.

\section{Conflict of interest}

The authors declare that they have no competing interest.

\section{References}

[1] Agarwal K, Varma R. Ocimum gratissimum L.: A medicinal plant with promising antiurolithiatic activity. Int J Pharm Sci Drug Res 2014; 6(1):78-81.

[2] Yachi L, Bennis S, Aliat Z, Cheikh A, Idrissi MOB, Draoui M, Bouatia M. In vitro litholytic activity of some medicinal plants on urinary stones. Afr. J. Urol 2018; 24(3):197-201.

[3] García-Perdomo HA, Solarte PB, España PP. Pathophysiology associated with forming urinary stones. Urol Colomb 2016; 25(2):118-25.

[4] Saha S, Verma RJ. Inhibition of calcium oxalate crystallization in vitro by an extract of Bergenia ciliate. Arab J Urol 2013; 11:187-92.

[5] Khan A, Khan SR, Gilani AH. Studies on the in vitro and in vivo antiurolithic activity of Holarrhena antidysenterica. Urol Res 2012; 40(6):671-81.

[6] Butterweck V, Khan S. Herbal Medicines in the Management of Urolithiasis: Alternative or Complementary? Planta Med 2009; 75(10):10951103.

[7] Dinan, L, Savchenko T, Whiting. P. Phytoecdysteroids in the genus Asparagus (Asparagaceae). Phytochemistry 2001; 56(6):569-76.

[8] Dassanayake MD, Clayton WD.A Revised Handbook of the Flora of Ceylon -Volume 14A A Balkema Publishers, Rotterdam, Netherlands, 2000: 94-98.

[9] Jayaweera DMA. Medicinal plants (Indigenous and exotic) used in Ceylon- Part III, National Science Council Sri Lanka, 1982: 262-65.

[10] Alok S, Sabharwal M, Mishra SB, Singh P, Singh M. In vitro evaluation on antiurolithiatic activity of roots of Asparagus racemosus Willd. Fl. \& Fauna (Jhansi) 2009; 15(1):163-66.

[11] Jagannath N, Chikkannasetty SS, Govindadas D, Devasankaraiah G. Study of antiurolithiatic activity of Asparagus racemosus on albino rats. Indian J Pharmacol 2012; 44(5):576-79.

[12] Alok S, Jain SK, Verma A, Kumar M, Mahor A, Sabharwal M. Plant profile, phytochemistry and pharmacology of Asparagus racemosus (Shatavari): A review. Asian Pac J Trop Dis 2013; 3(3):242-51.

[13] Hennequin C, Lalanne V, Daudon M, Lacour B, Drueke T.A new approach to studying inhibitors of calcium oxalate crystal growth. Urol Res 1993; 21:101-08.

[14] Napagoda M, Madhumadhavi N, Vimukthi K. Evaluation of antiurolithiatic potential in Crataeva religiosa: An in vitro study. Prayog Ras $2019 ; 3(2): 1-4$

[15] Devkar RA, Chaudhary S, Adepu S, Xavier SK, Chandrashekar KS, Setty MM. Evaluation of antiurolithiatic and antioxidant potential of Lepidagathis prostrata: A Pashanbhed plant. Pharm Biol 2016; 54(7):1237-45.

[16] Hess B, Nakagawa Y, Coe FL. Inhibition of calcium oxalate monohydrate crystal aggregation by urine proteins. Am J Physiol 1989; 257:99-106.

[17] Hodgkinson A. A combined qualitative and quantitative procedure for the chemical analysis of urinary calculi. J Clin Pathol 1971; 24(2):147-51.

[18] Mandel N. Mechanism of stone formation. Semin Nephrol 1996; 16(5):364-74.

[19] Alelign T, Petros B. Kidney stone disease: An update on current concepts. Adv Urol 2018; 3068365. doi:10.1155/2018/3068365

[20] Tiwari P, Kothiyal P, Ratan P. Antiurolithiatic effect of some polyherbal formulations used in experimentally induced urolithiasis: A review. Int Res $J$ Pharm 2017; 8(5):14-22. 